\section{A organização retórica do artigo de opinião no contexto do vestibular}

The rhetorical organization of opinion articles in the context of a university admission test

Wiliam César RAMOS (UEM) wiliamramos_ple@yahoo.com Cíntia BICUDO (UEM) cintia.bicudo@hotmail.com

Luciana Cristina Ferreira Dias Di RAIMO (UEM) diaslucian@yahoo.com

Recebido em: 21 de jan. de 2019. Aceito em: 15 de maio de 2019.
RAMOS, Wiliam César; BICUDO, Cíntia; RAIMO, Luciana Cristina Ferreira Dias Di. A organização retórica do artigo de opinião no contexto do vestibular. Entrepalavras, Fortaleza, v. 9, n. 2, p. 93-111, maio-ago/2019.

Resumo: Nesta pesquisa, realizamos uma análise documental de vinte artigos de opinião produzidos no vestibular de inverno de 2016 da Universidade Estadual de Maringá (UEM), considerados ótimos pela Comissão Central do Vestibular Unificado (CVU), com o objetivo de identificar a sua estrutura retórica e contrastá-la com a do artigo de opinião produzido no contexto jornalístico. Pautamo-nos na definição de gênero proposta por Bakhtin (1997, 2006), no modelo CARS (Create A Research Space) de Swales (1990), e na adaptação do modelo CARS, proposto por Oliveira (2004) para o gênero Artigo de opinião. Os resultados revelam que a estrutura retórica dos artigos produzidos no contexto do vestibular apresenta diferenças com relação à estrutura retórica daqueles produzidos na esfera jornalística.

Palavras-chave: Função retórica. Artigo de opinião. Vestibular. 
V. $9(2)$

93-111

maio-ago

2019

Abstract: In this study, we analyze twenty opinion articles produced by students taking the 2016 winter admission test of the state university of Maringá (UEM), Brazil, graded as excellent by the board of examiners (Comissão Central do Vestibular Unificado (CVU)), aiming to identify and compare the rhetorical structure of this genre with that of the opinion articles produced in the journalistic context. Our analysis is based on Bakhtin (1997, 2006)'s genre concept, Swales (1990)'s CARS model, and Oliveira (2004)'s opinion article rhetorical model. The results show that there are differences between the rhetorical structure of the opinion articles produced in the university admission test and the rhetorical structure of those produced in the journalistic context.

Keywords: Rhetorical function. Opinion article. University admission test.

\section{Introdução}

O ensino de gêneros textuais tem-se tornado imprescindível nas aulas de Língua Portuguesa do ensino médio da região norte do Paraná, tendo em vista que, desde 2008, a prova de redação do vestibular da Universidade Estadual de Maringá (UEM), um dos mais concorridos do país, solicita a produção de um gênero textual.

A relevância dessa proposta tem sido atestada pelo interesse de pesquisadores da própria universidade, que desenvolveram estudos sobre as características prototípicas dos gêneros que podem ser solicitados na situação do vestibular (ANTONIO; NAVARRO, 2017), e propostas didáticas voltadas ao ensino dos gêneros requeridos no vestibular (CORSI; RITTER; HILA, 2015).

Dentre os gêneros cobrados desde 2008, selecionamos o artigo de opinião pelos seguintes motivos: 1) existência de uma instabilidade na estrutura composicional em sua circulação social (COSTA, 2009); 2) valorização da posição social do autor desse gênero como maneira de dar credibilidade aos argumentos (ZANINI, 2017); 3) reação-resposta deste gênero em relação a outros enunciados (RODRIGUES, 2007).

Considerando esse contexto, o nosso objetivo é identificar a sua estrutura retórica e contrastá-la com a do artigo de opinião produzido em contexto jornalístico. Para isso, realizaremos uma análise documental de vinte artigos de opinião produzidos no vestibular de inverno de 2016 e considerados ótimos pela Comissão Central do Vestibular Unificado (CVU). Escolhemos as redações dessa edição por serem recentes e já estarem disponibilizadas para estudos como este, o que permite resultados atuais que podem ajudar professores e futuros candidatos. As redações foram identificadas com a sigla $\mathrm{AO}$ (artigo de opinião) e numeradas de 1 a 20 (AO1, AO2, etc). 
Tendo em vista que a seção Direito de uso das redações, no manual do candidato, informa que, após a publicação do resultado final do processo seletivo, a redação passa a ser propriedade da UEM, podendo ser utilizada em pesquisas, não foi necessário submeter esta pesquisa ao Comitê de Ética da universidade. Tivemos apenas o cuidado de digitar as redações para a análise e citação a fim de evitar que a caligrafia do candidato fosse exposta.

Para a nossa discussão, pautamo-nos na definição de gênero a partir da interação social proposta por Bakhtin (1997, 2006); no modelo CARS (Create A Research Space) de Swales (1990) e na adaptação desse modelo para o artigo de opinião proposta por Oliveira (2004). Quanto à organização deste trabalho, primeiramente, apresentaremos o conceito de gênero; em seguida, trataremos do artigo de opinião em sua circulação social e no contexto do vestibular; e, por fim, identificaremos a organização retórica do artigo de opinião no contexto do vestibular contrastando-a com o modelo de Oliveira (2004) e teceremos considerações finais.

\section{Gêneros textuais}

Segundo Silva (2018), os comandos de produção da prova de redação do vestibular da UEM são norteados pelo dialogismo bakhtiniano (BAKHTIN, 1997, 2006). Nessa vertente, a comunicação verbal é considerada em relação à situação de uso e sempre acompanhada por atos sociais.

A comunicação verbal não poderá jamais ser compreendida e explicada fora desse vínculo com a situação concreta. A comunicação verbal entrelaça-se inextricavelmente aos outros tipos de comunicação e cresce com eles sobre o terreno comum da situação de produção (BAKHTIN, 2006, p. 126).

Para Bakhtin (1997), o conteúdo temático, o estilo e a estrutura composicional são marcados pela esfera de comunicação em que o enunciado se encontra: "[...] cada esfera de utilização da língua elabora seus tipos relativamente estáveis de enunciados, sendo isso que denominamos gêneros do discurso" (BAKHTIN, 1997, p. 279). Nos termos bakhtinianos, o conceito de gênero do discurso refere-se a formas típicas de enunciados realizadas com finalidades e condições específicas nas situações de interação social. Em cada contexto, o tipo de organização do discurso é diferente, consequentemente, os gêneros 
V. $9(2)$

93-111

maio-ago

2019

discursivos são diferentes (LOPES-ROSSI, 2002). Por exemplo, quando conversamos com uma pessoa pelo telefone é diferente de quando ligamos e deixamos um recado; o tema, os interlocutores e a esfera de circulação são os mesmos, mas o gênero é diferente, pois, no recado, não há diálogo.

O repertório de gêneros discursivos existentes engloba todas as atividades humanas constituídas pela linguagem: a carta pessoal entre amigas adolescentes que trocam informações, entrevista de seleção para emprego, orçamento do marceneiro para o cliente, telegrama de pêsames entre parentes, etc. (MOTTA-ROTH, 2004, p. 2).

Bakhtin (1997) divide os gêneros em dois grupos: os gêneros primários e os secundários. Os gêneros primários são mais simples, pois fazem parte da comunicação cotidiana, como uma carta pessoal ou um bilhete. Já os secundários aparecem em circunstâncias mais complexas de uma comunicação cultural, como um romance, um teatro, um artigo científico, um artigo de opinião etc.

\section{0 gênero Artigo de opinião na circulação social}

O artigo de opinião geralmente é encontrado em revistas e em jornais; é um gênero marcado por expressar a tese/opinião do seu autor. A tese é uma hipótese escolhida pelo articulista, que considera a possibilidade de comprová-la, por isso o lugar que o observador ocupa é único. Para Zanini (2017), o ponto de vista pelo qual o autor vê o objeto ou o fato é essencial para construir a sua tese. As provas e os fatos fortalecem a tese e "os valores aí embutidos garantem a força do argumento, cujo objetivo é tornar clara e dar credibilidade à opinião" (ZANINI, 2017, p. 51).

O artigo de opinião, em circulação social, é escrito para comentar algo que já foi dito (fato jornalístico), geralmente uma questão polêmica ou controversa. O jornalista constrói o seu discurso a partir de outros e, ao mesmo tempo, dialoga com o discurso potencial do seu leitor.

O artigo de opinião é constituído de outros discursos sobre os fatos comentados e de antecipações das objeções do leitor, para fazer aderir ao seu ponto de vista e para criticar os outros com os quais mantém uma relação de conflito. Tudo isso comprova que o texto é o lugar de circulação de discursos, mostrados ou não, e o sujeito não é a fonte do sentido, mas o constrói no trabalho incessante com o já dito (CUNHA, 2010, p. 193). 
Esse gênero é fundamentalmente dialógico, porque sempre terá relação com o já dito, com outros discursos. O artigo de opinião se "[...] constitui como uma reação-resposta a esses enunciados da atualidade (o já dito) e busca a reação-resposta ativa do seu interlocutor" (RODRIGUES, 2007, p. 173).

Nesse gênero, um jornalista ou um colaborador do jornal apresenta o seu ponto de vista acerca dos acontecimentos da atualidade. Na acepção de Rodrigues (2007), esses fatos podem ser usados pelo articulista como objeto de crítica, de questionamento e/ou de argumento para o seu discurso.

Além disso, Uber (2008, p. 4) afirma que "o discurso argumentativo, presente no artigo de opinião, tem como finalidade a persuasão ou convencimento do interlocutor, com intenções de que ele compartilhe uma opinião ou realize uma determinada ação" (UBER, 2008, p.4). É prototípico desse gênero textual a discussão de assuntos sociais; consequentemente, o autor marca posição, negociação, aceitação ou refutação de argumentos. Para tal argumentação, no ideário de Cunha (2010), os autores também podem usar narrativas como estratégia argumentativa.

O reconhecimento social do articulista atribui credibilidade ao texto e, muitas vezes, funciona como argumento de autoridade, por isso, geralmente, o texto está assinado. Em contrapartida, no contexto do vestibular, o candidato, ao escrever o seu artigo de opinião, não tem esse reconhecimento social para dar credibilidade ao seu texto.

\section{O gênero Artigo de opinião no contexto do vestibular}

Bronckart (2003), com base nos postulados teóricos de Bakhtin (2006), elenca os seguintes aspectos como categorias do contexto de produção que norteiam a produção de um gênero textual: i) esfera da comunicação; ii) identidade social dos interlocutores; iii) finalidade; iv) concepção do referente (o conteúdo temático); v) suporte material; e vi) relação interdiscursiva.

A partir das categorias apresentadas, comparamos o gênero Artigo de opinião em sua circulação social da esfera jornalística com o produzido no contexto de vestibular. Na situação social, o autor é um jornalista ou um especialista no assunto, tem de uma semana a 15 dias para escrever (dependendo da empresa), às vezes lhe é solicitado um assunto específico, mas ele, como autoridade no assunto, pode delimitar 
V. $9(2)$

93-111

maio-ago

2019

o tema, priorizando o que acha importante ou o que lhe é mais familiar. Além disso, o texto é escrito para leitores interessados na opinião do articulista sobre o assunto. Quanto à situação do vestibular, o sujeito candidato, que é o autor, tem, em média, 17 ou 18 anos ${ }^{1}$, bem como apenas quatro horas para responder às 20 questões somatórias de Língua Portuguesa, literaturas em Língua Portuguesa e língua estrangeira, e produzir duas redações ${ }^{2}$. Além disso, o tema é imposto pelo comando da prova, e o candidato escreve para uma banca de professores de Língua Portuguesa, cujo único objetivo é avaliar o texto do candidato.

Desde 2008, o gênero Artigo de opinião foi solicitado em três ocasiões: no vestibular de verão de 2012, no vestibular de inverno de 2014 e no vestibular de inverno de 2016. Para este trabalho, optamos pelo vestibular de inverno de 2016 por ser o mais recente, possibilitando, assim, resultados mais atuais que podem auxiliar professores e futuros candidatos.

As redações analisadas foram produzidas a partir do comando apresentado no Quadro 1.

Quadro 1 - Comando de produção do vestibular de inverno 2016.

Contexto de produção: Você é psicólogo(a), especialista em comportamento humano, e sua atual pesquisa trata da empatia. Convidado(a) a escrever para um jornal de grande circulação, você tem que defender uma necessidade urgente em nossa sociedade: a de o ser humano desenvolver a capacidade de se colocar no lugar do outro, como forma de tentar compreender seus sentimentos ou seu ponto de vista. Isso para melhorar a própria vida e transformar o mundo.

Comando de produção: A partir do contexto de produção acima apresentado, redija um ARTIGO DE OPINIÃO sobre a importância de as pessoas serem empáticas como forma de melhorar suas vidas e de transformar o mundo colocando-se no lugar do outro. Sustente sua tese apoiando-se em, pelo menos, dois argumentos. Você deverá assinar o artigo como "Colaborador" ou "Colaboradora". Seu texto deverá ter o mínimo de 10 e o máximo de 15 linhas.

Fonte: Universidade Estadual de Maringá (2016, p. 3).

O comando de produção aparece dividido em duas partes. A primeira, designada Contexto de produção, cria uma situação fictícia e indica um papel social para o candidato ocupar no momento da escrita. A segunda parte, Comando de produção, delimita o gênero, o tema, a quantidade de linhas e a tese que o candidato tem que defender. Para

\footnotetext{
${ }^{1}$ Observamos as características dos aprovados no vestibular de inverno da UEM em 2016 por meio do questionário socioeducacional preenchido por eles no momento da inscrição. Disponível em: <https://www.npd.uem.br/cvu/evento.zul?id=8>. Acesso em: 12 dez. 2018.
}

2 Manual do Candidato do vestibular de inverno de 2016 da UEM. Disponível em: <https://www.npd.uem.br/cvu/relatorios/manual_candidato_8.pdf> Acesso em: 12 dez. 2018. 
responder adequadamente a esse comando, o candidato deve apresentar argumentos que defendem a necessidade de empatia. Desse modo, não há a possibilidade de posicionar-se de outra maneira. Isso ocorre justamente em virtude de a temática não ser polêmica e o próprio comando já materializar a posição que deve ser ocupada (a favor da empatia).

Ademais, vale destacar que a situação de produção é artificial e, nesse caso, o sujeito-candidato além de não ocupar o lugar de jornalista reconhecido/colaborador legitimado no assunto deve, ainda, marcar, num jogo de "faz de contas", uma posição social legitimada.

O tema a ser discutido não é fruto de uma escolha do aluno, diferentemente do que ocorre na esfera jornalística, mas já é determinada pelo próprio comando que impõe a temática que deve ser problematizada.

As condições de produção atinentes ao vestibular em tela determinam, em função do comando, uma situação de produção do artigo de opinião mais artificial: (i) o candidato-aluno deve assumir uma posição social que não é a sua (é preciso falar do lugar de psicólogo sem ser/ter tal experiência), (ii) a esfera de circulação ("jornal de grande circulação") não faz parte de suas práticas de escrita, bem como o texto produzido no vestibular não circula, (iii) a tese "defender uma necessidade urgente em nossa sociedade: a de o ser humano desenvolver a capacidade de se colocar no lugar do outro" é (im)posta pelo próprio comando.

Sintetizamos as diferenças entre os dois contextos de produção do artigo de opinião e apresentamos no quadro a seguir.

Quadro 2 - Contexto de produção no vestibular

\begin{tabular}{|c|c|c|}
\hline \multirow{2}{*}{ CATEGORIAS } & \multicolumn{2}{|c|}{ CONTEXTO DE PRODUÇÃO } \\
\cline { 2 - 3 } & VESTIBULAR & CIRCULAÇÃO SOCIAL \\
\hline $\begin{array}{c}\text { Posição social do } \\
\text { autor }\end{array}$ & Candidato & Jornalista ou especialista na área \\
\hline Interlocutor & Banca de professores & Leitores em geral \\
\hline Suporte material & $\begin{array}{c}15 \text { linhas da folha } \\
\text { de prova }\end{array}$ & $\begin{array}{c}\text { Jornais e revistas } \\
\text { (impresso ou online) }\end{array}$ \\
\hline $\begin{array}{c}\text { Esfera da } \\
\text { comunicação }\end{array}$ & Escolar/acadêmica & Jornalística \\
\hline Finalidade/ intuito & Ser aprovado no vestibular & Expor o seu ponto de vista \\
\hline
\end{tabular}

Fonte: Elaboração própria. 
V. 9 (2)

93-111

maio-ago

2019

\section{Organização retórica}

Para a análise da organização retórica, construímos um corpus com vinte redações produzidas a partir desse comando e consideradas 'ótimas' pela CVU. Primeiro, numeramos as redações de um a vinte e, em seguida, digitamo-las. Verificamos que todas possuem título, 95\% apresentam assinatura e 95\% utilizam a primeira pessoa do singular.

Para Biasi-Rodrigues, Hemais e Araújo (2009), a obra pioneira no campo da sociorretórica de gêneros é Genre analysis: English in academic and research settings (SWALES, 1990), na qual o autor descreve a estrutura retórica do gênero introdução de artigo de pesquisa, organizando-o em três movimentos retóricos (moves): estabelecer o território; estabelecer o nicho; e ocupar o nicho. Esses movimentos, por sua vez, subdividemse em movimentos mais específicos chamados de passos (steps).

Acreditamos que a maior contribuição de Swales aos estudos de gêneros, em termos analítico-metodológicos e pedagógicos, seja esse seu modelo de análise de gêneros textuais, que se caracteriza pela regularidade dos movimentos retóricos, com a força e flexibilidade suficientes para ser aplicado nos mais variados contextos (BIASI-RODRIGUES; HEMAIS; ARAÚJO, 2009, p. 32).

Com base no modelo CARS de Swales (1990), Oliveira (2004) analisou a organização retórica de dez artigos de opinião do jornal 0 povo (do Ceará) e propôs um modelo com quatro unidades retóricas apresentado, a seguir, no Quadro 3.

Quadro 3 - Organização retórica do gênero Artigo de opinião

\section{Unidade retórica 1 - Apresentação do tema}

Subunidade $1 \mathrm{~A}$ - Apresentando o fato jornalístico e/ou

Subunidade $1 \mathrm{~B}$ - Apresentando o(s) antecedente(s) do tema em questão

\section{Unidade retórica 2 - Apresentação de uma tomada de posição}

Subunidade 1 - Formulando uma tese e/ou

Subunidade 2 - Apresentando diferente(s) argumento(s) que justificam a tese

\section{Unidade retórica 3 - Avaliação}

Subunidade 1A - Apresentando processo(s) estimativo(s) de juízo(s) de valor(es) e/ ou

Subunidade 1B - Apresentando causa(s) e consequência(s)

\section{Unidade retórica 4 - Conclusão}

Subunidade 1A - Apresentando conclusão(ões) e/ou

Subunidade 1B - Indicando perspectiva(s)

Fonte: Oliveira (2004, p. 73). 
A hipótese que defendemos é a de que a organização retórica dos artigos produzidos no contexto do vestibular apresenta diferenças quando comparada à organização do gênero em situação social, já que os contextos de produção e recepção são diferentes. Isso posto, a partir de Oliveira (2004), analisamos vinte artigos de opinião produzidos no vestibular de inverno de 2016 da UEM, classificados como ótimos pela instituição, com o objetivo de identificar a sua estrutura retórica. Para as unidades ou movimentos retóricos, utilizaremos o termo 'função retórica', pois se referem "[...] à função comunicativa que um trecho textual cumpre num determinado gênero" (RAMOS, 2011, p. 23).

Nos artigos de opinião analisados, encontramos três funções retóricas (FR) gerais: a primeira refere-se à apresentação do tema (FR1); a segunda diz respeito à posição assumida (FR2); e a terceira corresponde à conclusão (FR3).

As funções retóricas 1 e 2 estão subdivididas em subfunções retóricas para representar movimentos retóricos específicos, a saber: Função Retórica 1 - Apresentação do tema (subfunções 1 A - Apresentar um fato jornalístico; $1 \mathrm{~B}$ - Apresentar o(s) antecedente(s) do tema); Função Retórica 2 - Apresentação de uma tomada de decisão (subfunções $2 \mathrm{~A}-$ Formular uma tese; $2 \mathrm{~B}-$ Apresentar argumento(s) que justificam a tese; $2 \mathrm{C}$ - Provocar reflexões para justificar a tese; $2 \mathrm{D}$ - Apresentar possíveis contraargumentos; e 2E - Mencionar a posição social como autoridade no assunto); e Função Retórica 3 - Conclusão.

A subfunção $2 \mathrm{~A}$ - Formular uma tese foi a mais recorrente, aparecendo em $100 \%$ do corpus, provavelmente em função do próprio comando de produção que estabelece a tese a ser defendida pelo candidato.

O modelo de organização retórica que propomos (Quadro 4) não contempla a função retórica referente à 'Avaliação', presente no modelo proposto por Oliveira (2004), pois entendemos que, por se tratar de um artigo de opinião, a avaliação, no sentido de atribuir juízo de valor a algo, está presente em todo o texto; nem tampouco a função retórica referente à indicação de perspectivas, na 'Conclusão', pois não ocorreu no nosso corpus.

Por outro lado, o modelo contempla três novas subfunções que não constam no modelo de Oliveira (2004), a saber: $2 C$ - Provocar reflexões para justificar a tese, $2 \mathrm{D}$ - Apresentar possíveis contra-argumentos e $2 E-M e n c i o n a r$ a posição social como autoridade no assunto. Na sequência, apresentamos o modelo completo no Quadro 4: 
V. $9(2)$

93-111

maio-ago 2019
Quadro 4 - Organização retórica dos artigos de opinião produzidos no vestibular

\begin{tabular}{|l|l|c|}
\hline Função Retórica 1 & Apresentação do tema & Ocorrência \\
\hline Subfunção 1A & Apresentar um fato jornalístico e/ou & $70 \%$ \\
\hline Subfunção 1B & Apresentar o(s) antecedente(s) do tema & $75 \%$ \\
\hline \multicolumn{2}{|l|}{ Função Retórica 2 } & Apresentação de uma tomada de posição \\
\hline Subfunção 2A & Formular uma tese e/ou & $100 \%$ \\
\hline Subfunção 2B & Apresentar argumentos que justificam a tese e/ou & $90 \%$ \\
\hline Subfunção 2C & Provocar reflexões para justificar a tese e/ou & $55 \%$ \\
\hline Subfunção 2D & Apresentar possíveis contra-argumentos e/ou & $35 \%$ \\
\hline Subfunção 2E & Mencionar a posição social como autoridade no & $85 \%$ \\
\hline & assunto & $95 \%$ \\
\hline Função Retórica 3 & Conclusão & \\
\hline
\end{tabular}

Fonte: Elaboração propria.

A Subfunção $1 A$ - Apresentar um fato jornalístico ocorre no início do texto e apresenta um fato relacionado à sociedade ou à experiência do psicólogo, dessa forma servindo como contextualização ou fundamentação da tese defendida. No primeiro caso, o autor presume que o leitor de jornal tenha conhecimento de fatos relacionados à sociedade por já terem sido noticiados profusamente; no segundo, o fato relatado pelo psicólogo assume caráter jornalístico por ser apresentado como notícia integrando a temática do artigo de opinião.

\section{[AO11]}

A sociedade, no âmbito local ou mundial, ferem (sic) a empatia cometendo, desde grosserias públicas, práticas mais graves e frequentes, como o terrorismo.

$[\mathrm{AO} 2]$

[...] um menino com 17 anos e um quadro depressivo agudo, os pais acharam que era frescura já que diziam que ele tinha tudo e nem sequer pararam para entender o que se passava com ele, por isso, não houve o tratamento necessário e o menino veio a cometer suicídio. 
A Subfunção $1 B$ - Apresentar o(s) antecedente(s) do tema traz, geralmente, definições, citações e generalizações para contextualizar a tese.

[AO3]

A empatia é a capacidade de entender as emoções de outras pessoas a partir da permuta de valores entre estas.

[AO4]

Thomas Hobbes já dizia: "o mundo é uma constante guerra de todos contra todos". A fim de mudar isso, doutrinas pacíficas (como o cristianismo e o budismo) adotaram lemas que consideram o outro uma extensão do "eu", promovendo o respeito, paz e compreensão.

A Subfunção 2A - Formular uma tese apresenta a tese defendida pelo autor que, no caso específico do vestibular em tese, já é de antemão solicitada pelo próprio contexto e comando de produção da prova de redação.

[AO11]

O dia-a-dia do cidadão seria tão mais saudável se tratado com doses de gentileza e alteridade.

[AO14]

[...] é justamente a capacidade de se colocar no lugar do outro - a empatia - é que transformará o mundo.

A Subfunção 2B - Apresentar argumentos que justificam a tese expõe os argumentos que fundamentam a tese defendida, por exemplo o argumento por meio de exemplificações e o argumento de autoridade, dentre outras estratégias.

[AO7]

Grandes exemplos comprovam isso: Madre Tereza de Caucutá (sic) que tanto fez pelos pobres, doentes. Zilda Arns, que até colocou sua vida em risco para empatizar, foi ela a criadora da multi mistura (sic) contra a desnutrição infantil. 
V. 9 (2)

93-111

maio-ago

2019

[AO10]

Além disso, segundo o filósofo australiano Roman Krznaric "o hábito de empatizar pode criar laços humanos que fazem valer a pena viver [...] sem isso somos seres menores, e apenas parte do que poderíamos ser".

A Subfunção 2C - Provocar reflexões para justificar a tese traz questões que convidam o leitor a refletir sobre a tese.

\section{[AO11]}

Por que não se colocar no lugar da vítima e tentar entender que ela, muitas vezes, não fez nada de ruim ao povo muçulmano para ser condenada segundo suas crenças? Por que não se colocar no lugar do muçulmano e tentar entender que ele tem uma crença e o mundo deve respeitá-la?

\section{[AO17]}

E se mudarmos de perspectiva?

Na Subfunção 2D - Apresentar possíveis contra-argumentos, o autor aponta visões contrárias à tese defendida.

\section{[AO17]}

Embora haja os que têm conviç̧ão de que ouvir outrem é perda de tempo, quiçá conversar e compreender genuinamente os sentimentos alheios, [...]

\section{[AO20]}

Há quem acredite ser mais importante estar sempre em primeiro lugar, não se interessando pelo outro por nunca ter vivenciado a Empatia.

Na Subfunção 2E - Mencionar a posição social como autoridade no assunto, o autor apresenta-se como psicólogo(a) especializado(a) no assunto conforme solicitado pelo contexto e pelo comando de produção da redação, ainda que tal posicionamento represente um simulacro das condições de produção reais de um artigo de opinião em que um sujeito com conhecimento na área discute sobre um tema. 
[AO1]

[... ] como psicólogo engajado em pesquisas com essa temática, $[\ldots]$

[AO6]

Como psicóloga e especialista em comportamento humano, $[\ldots]$

A Função retórica 3 - Conclusão ocorre no último parágrafo da redação e traz conclusões que retomam a tese defendida pelo autor. Esta função não possui subfunções como no modelo de Oliveira (2004), provavelmente por se tratar do contexto de vestibular e não de artigos de opinião redigidos por especialistas que, em função da experiência como profissionais e do espaço disponível no jornal, podem, além de elaborar conclusões, também indicar perspectivas.

\section{[AO12]}

Dessa forma, a empatia traz benefícios para nós mesmos por nos agrega (sic) auto conhecimento (sic), e também nos faz compreender as atitudes do outro, ajudando na convivência e redução de problemas de ambos.

\section{[AO13]}

Agindo de maneira empática, nós passamos a tratar o outro com mais respeito e mais compreensão. Isso é essencial para uma sociedade não viver em meio ao caos e com pessoas egocêntricas.

No que diz respeito à paragrafação e posição das funções retóricas, 60\% dos artigos estão divididos em três parágrafos, e as subfunções $1 A$ - Apresentar um fato jornalístico, $1 B$ - Apresentar o(s) antecedente(s) do tema e $2 \mathrm{~A}$ - Formular uma tese aparecem, geralmente, no título ou início do artigo para apresentar e contextualizar a tese defendida, ao passo que a função retórica 3 - Conclusão ocorre no final do artigo, retomando-a. Essa sequência está refletida no modelo que propomos, entretanto faz-se importante ressaltar que as funções retóricas são cíclicas alternando-se segundo a argumentação e o estilo do candidato, autor do artigo de opinião, conforme mostra o Quadro 5. 
V. 9 (2)

93-111 maio-ago 2019

Quadro 5 - Ordem de ocorrência das funções retóricas dos artigos de opinião do contexto de vestibular

\begin{tabular}{|l|l|}
\hline$A O$ & \multicolumn{1}{|c}{ ORGANIZAÇÃO RETÓRICA } \\
\hline$A O 1$ & $2 A-1 B-2 D-2 E-2 B-3 B$ \\
\hline$A O 2$ & $2 A-1 B-2 C-2 E-1 A-3 B-2 C$ \\
\hline$A O 3$ & $1 B-2 A-2 B-2 E-1 A-3 B$ \\
\hline$A O 4$ & $2 A-1 B-1 A-2 E-2 A-2 B-2 C$ \\
\hline$A O 5$ & $2 A-1 B-1 A-2 E-2 A-2 B-3 A-3 B-3 A$ \\
\hline$A O 6$ & $2 C-1 A-2 E-2 A-3 A$ \\
\hline$A O 7$ & $1 A-1 B-2 C-2 A-2 B-3 B$ \\
\hline$A O 8$ & $1 A-2 E-2 A-2 B-2 D-3 A$ \\
\hline$A O 9$ & $2 A-1 B-2 E-1 A-2 A-2 B-3 A$ \\
\hline$A O 10$ & $2 E-1 A-1 B-2 C-2 A-2 B-3 A$ \\
\hline$A O 11$ & $2 A-2 E-1 A-2 A-2 C-2 B-2 C-3 B$ \\
\hline$A O 12$ & $2 A-1 B-2 D-2 E-2 A-2 B-3 A-2 B-3 B$ \\
\hline$A O 13$ & $2 A-1 A-1 B-2 A-2 B-3 B-3 A$ \\
\hline$A O 14$ & $1 A-1 B-2 E-2 A-2 D-1 A-2 A-2 B-3 B-3 A-1 A$ \\
\hline$A O 15$ & $2 A-1 A-2 E-2 A-2 B-3 B$ \\
\hline$A O 16$ & $2 C-1 B-2 D-2 A-2 E-2 A-2 B-3 A$ \\
\hline$A O 17$ & $2 C-1 A-2 D-2 A-2 E-2 A-2 B-3 B-3 A$ \\
\hline$A O 18$ & $2 A-1 B-2 E-2 A-2 B-2 C-2 B-3 B$ \\
\hline$A O 19$ & $2 A-2 C-1 B-2 A-2 B-3 B$ \\
\hline$A O 20$ & $2 A-1 B-2 D-2 E-2 A-2 B-2 A-2 C-2 B-3 B$ \\
\hline
\end{tabular}

Fonte: Elaboração própria.

Em alguns casos, duas funções retóricas estão sobrepostas em um mesmo excerto, como ocorre no $\mathrm{AO} 5$, em que a tese de que tragédias poderiam ser reduzidas ou evitadas compõe parte da argumentação que sustenta outra tese, a de que é necessário praticar a empatia como forma de melhorar o mundo. Isso significa que o escopo de realização de uma determinada função retórica não se restringe ao nível do sintagma, da sentença ou do parágrafo, portanto a sua identificação depende da combinação de aspectos lexicais, gramaticais e retóricos, além da posição em que a função retórica ocorre no texto.

[AO5]

[FR2A] $\rightarrow[\ldots]$ a empatia e a urgente necessidade da sua prática frequente para a construção de uma (sic) mundo e vida melhores. [FR2B] $\rightarrow$ Dada a estrutura sociológica na qual 
estamos inseridos, a prática da alteridade tem se tornado cada vez mais escassa, culminando num cotidiano caótico que se reflete, na esfera individual, em agrupamentos de pessoas desconexas e, em âmbito global, nova onda de conflitos entre nações, especialmente de cunho étnico. [FR2B/FR2A] $\rightarrow$ Em suma, tragédias em diversos níveis que poderiam ser reduzidas - ou até evitadas - caso as pessoas agissem de forma empática.

Comparando o artigo de opinião produzido no contexto do vestibular com o produzido na esfera jornalística, constatamos que, em ambos os casos, há uma contextualização da tese defendida por meio da apresentação de um fato jornalístico e de antecedentes do tema. A tese é sustentada por argumentos que a justificam como forma de conseguir a adesão do leitor.

Tendo em vista que, no contexto do vestibular, o objetivo é obter uma boa nota na redação para ser aprovado, o autor pode lançar mão de recursos que podem impressionar positivamente a banca de correção, tais como o levantamento de questões reflexivas e a apresentação de possíveis contra-argumentos, pois ressaltam o caráter dialógico do gênero Artigo de opinião, bem como a retomada da tese na conclusão, pois demonstra a habilidade do candidato de manter o foco do texto.

A partir disso, podemos considerar que, apesar de emular o artigo de opinião da esfera jornalística, o artigo de opinião no contexto escolar possui especificidades retóricas oriundas das suas condições de produção.

Ramos (2011), a partir de Swales e Feak (2009), destaca que muitos gêneros que são tratados separadamente estão, na verdade, interligados. Bonini (2010), ao caracterizar os gêneros presentes em um jornal, define o artigo de opinião como um gênero livre e autônomo, porque possui uma unidade textual independente. Ao observarmos, porém, o artigo de opinião no contexto de vestibular, constatamos que ele deixa de ser "livre e autônomo" e passa a estar relacionado com outros gêneros, como o texto de apoio e o comando de produção.

A relação entre os artigos de opinião e o texto de apoio nesse vestibular é marcada por menções ao pesquisador Roman Krznaric encontradas nas redações AO10 e AO20. Esse filósofo foi o utilizado pelo autor do texto de apoio para definir empatia.

A relação entre os artigos de opinião e o comando ficou marcada pela tese defendida e pela menção explícita da posição social solicitada 
V. $9(2)$

93-111

maio-ago 2019

no comando. Os artigos de opinião na circulação social, geralmente, não apresentam a posição social do autor no texto, porque o autor é apresentado anteriormente, ou seja, o leitor já sabe o nome e a profissão do autor antes de começar a ler o texto. Também é muito comum que os autores escrevam com certa frequência para determinados websites, revista ou jornal, assim, o leitor mais assíduo já conhece o articulista. O Quadro 6 contrasta a organização retórica do artigo de opinião produzido no contexto do vestibular, o modelo proposto neste trabalho, com a organização retórica do artigo de opinião na circulação social, o modelo proposto por Oliveira (2004).

Quadro 6 - Comparação entre e a organização retórica do artigo de opinião no contexto do vestibular e a organização retórica do artigo de opinião na circulação social (OLIVEIRA, 2004)

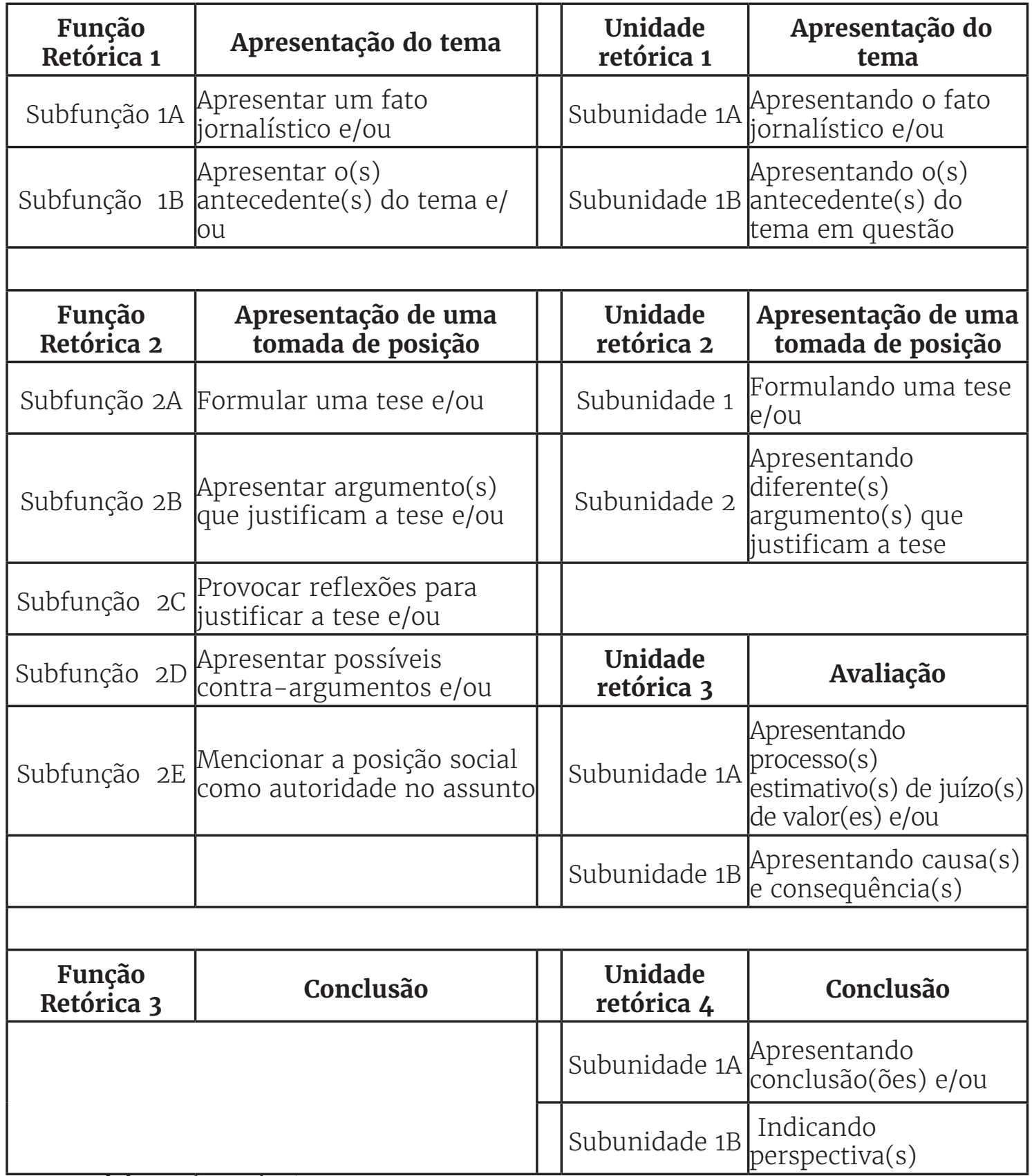




\section{Considerações finais}

A partir do modelo CARS (Create a Research Space) (SWALES, 1990) adaptado por Oliveira (2004) para o gênero Artigo de opinião, realizamos uma pesquisa com vinte artigos de opinião produzidos no vestibular de inverno de 2016 da UEM para identificar a estrutura retórica desse gênero textual.

A análise comparativa entre o modelo de Oliveira (2004) e o modelo que propomos demonstra que as especificidades da posição social do autor, interlocutor, suporte material, esfera de comunicação e finalidade do contexto do vestibular influenciaram diretamente a organização retórica do artigo de opinião nessa esfera.

Tendo em vista que o gênero Artigo de opinião é um gênero privilegiado dentre os solicitados em vestibulares, os resultados deste estudo contribuem para o aprimoramento dos conhecimentos sobre esse gênero textual tanto por parte dos alunos aspirantes a uma vaga na universidade como para o ensino de gêneros textuais em geral.

\section{Referências}

ANTONIO, J. D.; NAVARRO, P. (Org.). Gêneros textuais em contexto de vestibular. Maringá: Eduem, 2017.

BAKHTIN, M. Os gêneros do discurso. I - Problemática e definição e II $\mathrm{O}$ enunciado unidade de comunicação verbal. In: BAKHTIN, M., Estética da criação verbal. Tradução de Maria Ermantina G.G. Pereira. 2. ed. São Paulo: Martins Fontes, 1997. p.277-327.

BAKHTIN, M. A interação verbal. In: BAKHTIN, M. Marxismo e Filosofia da Linguagem. Tradução de Michel Lahud e Yara Frateschi Vieira. 12. ed. São Paulo: Hucitec, 2006. p. 112 - 130.

BIASI-RODRIGUES, B.; HEMAIS, B.; ARAÚJO, J. C. Análise de gêneros na abordagem de Swales: princípios teóricos e metodológicos. In: B. BIASIRODRIGUES; J. C. ARAÜJO; S. C. T. SOUSA (Org.). Gêneros textuais e comunidades discursivas: um Diálogo com John Swales. Belo Horizonte: Autentica, 2009. p. 17-32.

BONINI, A. Os gêneros do jornal: o que aponta a literatura da área de comunicação no Brasil?. Linguagem em (Dis)curso, v. 4, n. 1, p. 205-231, set. 2010. Disponível em: <http://www.portaldeperiodicos.unisul. br/index.php/ Linguagem_Discurso/article/view/263/277>. Acesso em: 13 dez. 2018.

BRONCKART, Jean-Paul. Atividade de linguagem, textos e discurso: por um interacionismo sóciodiscursivo. São Paulo: EDUC, 2003.

CORSI, M. S.; RITTER, L. C. B.; HILA, C. V. D. (Org.). Pibid- Letras/PortuguêsUEM: alguns resultados didático-pedagógicos do letramento literário e da produção textual. São Carlos: Pedro\&João Editores, 2015. 
V. 9 (2)

93-111 maio-ago 2019
COSTA, Sérgio Roberto. Dicionário de gêneros textuais. 2. ed. Belo Horizonte: Autentica, 2009.

CUNHA, D. A. C. O funcionamento dialógico em notícias e artigo de opinião. In: A. P. DIONISIO; A. R. MACHADO; M.A. BEZERRA (Org.). Gêneros textuais e ensino. São Paulo: Parábola, 2010. p. 179-193.

LOPES-ROSSI, M. A. G. et al (Org.). Gêneros discursivos no ensino de leitura e produção de textos. Taubaté: Cabral Editora e Livraria Universitária, 2002.

MOTTA-ROTH, D. Questão de metodologia em análise de gêneros. União da Vitória: S, 2004. 18 p. Disponível em: < http://w3.ufsm.br/desireemroth/ algumas_publicacoes/Dsir\%20e-SIGET.doc >. Acesso em: 13 dez. 2018.

OLIVEIRA, C. M. M. A organização retórica de artigos de opinião na imprensa e no jornal escolar. 2004. 163f. Dissertação (Mestrado em Linguística) - Centro de Humanidades, Universidade Federal do Ceará, Fortaleza, 2004. Disponível em: < http://www.repositorio.ufc.br/ handle/ riufc/3607 >. Acesso em: 13 dez. 2018.

RAMOS, W. C. Um roteiro para a escrita de abstracts de artigos de pesquisa: estrutura retórica e técnicas de argumentação. 2011. 345 f. Tese (Doutorado em Linguística e Língua Portuguesa), Universidade Estadual Paulista, Faculdade de Ciências e Letras, Araraquara, 2011. Disponível em: <https://repositorio. unesp.br/bitstream/handle/11449/100270/ ramos_wc_dr_arafcl_arafcl. pdf? sequence=1\&isAllowed=y>. Acesso em: 16 maio 2019.

RODRIGUES, R. H. Os gêneros do discurso na perspectiva dialógica da linguagem: a abordagem de Bakhtin. In: MOTTA-ROTH, D. et al. Gếneros: teorias, métodos, debates. 2. ed. São Paulo: Parábola, 2007. p. 152-183.

SILVA, C. C. Caracterização dos comandos de produção textual da prova de redação do vestibular da UEM. 2018. 191 f. Dissertação (Mestrado em Letras) - Curso de Letras, Teorias Linguísticas e Literárias, Universidade Estadual de Maringá, Maringá, 2018. Disponível em: <http://www.ple.uem.br/defesas/ pdf/ccsilva.pdf>. Acesso em: 13 dez. 2018.

SWALES, J. M. Genre analysis: English in academic and research settings. Cambridge: Cambridge University Press, 1990.

SWALES, J. M.; FEAK, C. B. Abstracts and the writing of abstracts. Ann Arbor: The University of Michigan Press, 2009.

UBER, T. J.B. Artigo de opinião: estudos sobre um gênero discursivo. 23 f. TCC Curso de Programa de Desenvolvimento Educacional da Secretaria de Estado da Educação do Paraná, Universidade Estadual de Maringá, Maringá, 2008. Disponível em: <http://www.gestaoescolar.diaadia.pr.gov.br/arquivos/File/ producoes_pde/artigo_terezinha_jesus_bauer_uber.pdf $>$. Acesso em: 13 dez. 2018.

UNIVERSIDADE ESTADUAL DE MARINGÁ. Comissão Central do Vestibular Unificado. Vestibular UEM Inverno 2016. Prova 2 - Língua Portuguesa e Literaturas em Língua Portuguesa, Língua Estrangeira e Redação. Disponível em: <http://www.vestibular.uem.br/8/P2G1.pdf>. Acesso em: 13 dez. 2018. 
UNIVERSIDADE ESTADUAL DE MARINGÁ. Comissão Central do Vestibular Unificado. Questionário Socioeducacional dos Aprovados no vestibular de Inverno 2016. Disponível em: <https://www.npd. uem.br/cvu/evento. zul?id=8>. Acesso em: 13 dez. 2018.

ZANINI, M. Artigo de Opinião: do ponto de vista à argumentação. In: J. D. ANTONIO; P. NAVARRO (Org.). Gêneros textuais em contexto de vestibular. Maringá: Eduem, 2017. p. 42-58. 